Martins, A., Pereira, M., Andrade, R., Dattilio, F. M., Narciso, I., \& Canavarro, M. C. (2016). Infidelity in dating relationships: Gender-specific correlates of face-to-face and online extradyadic involvement. Archives of Sexual Behavior, 45(1), 193-205. doi:10.1007/s10508-015-0576-3

\title{
Infidelity in dating relationships: Gender-specific correlates of face-to-face and online extradyadic involvement
}

\begin{abstract}
This study examined the gender-specific correlates of face-to-face and online extradyadic involvement (EDI) in dating relationships. The sample consisted of 561 women ( $M$ age $=23.19$ years $)$ and 222 men $(M$ age $=23.97$ years $)$, all of whom reported being in an exclusive dating relationship for an average of 35 months. Participants completed the following self-report measures: Extradyadic Behavior Inventory, Attitudes toward Infidelity Scale, and Investment Model Scale. During the current relationship, men were more likely than women to report engagement in face-to-face physical/sexual EDI (23.4\% vs. 15.5\%) and online sexual EDI (15.3\% vs. $4.6 \%)$. Both men and women with a history of infidelity in a prior relationship were more likely to engage in EDI. More positive attitudes toward infidelity, lower relationship satisfaction, lower commitment, and higher quality of alternatives were significantly associated with EDI, regardless of gender. Women reporting infidelity of a partner in a prior relationship were more likely to engage in face-to-face and online emotional EDI; a longer relationship and a younger age at the first sexual encounter were significant correlates of the engagement in face-to-face emotional EDI. Women with higher education were approximately three times more likely to engage in online sexual EDI. Although men and women are converging in terms of overall EDI, men still report higher engagement in physical/sexual extradyadic behaviors, and the correlates of sexual and emotional EDI vary according to gender. This study contributes to a comprehensive approach of factors influencing the likelihood of EDI and encourages future research in this area.
\end{abstract}

KEY WORDS: Dating relationships; Extradyadic involvement; Gender differences. 


\section{INTRODUCTION}

In contemporary societies, although young people lack clear "rules" and expectations for dating (DeGenova \& Rice, 2005), sex and other intimate behaviors are still expected to be restricted to the primary relationship (Boekhout, Hendrick, \& Hendrick, 2003; O'Sullivan \& Ronis, 2013). This exclusivity norm has been reported across multiple cultures (e.g., de Roda, Martinez-Inigo, de Paul, \& Yela, 1999; Haavio-Mannila \& Kontula, 2003) and has been found to exist in different types of relationships (Treas \& Giesen, 2000). When the involvement in those exclusive behaviors occurs outside the primary relationship, such behaviors are named extradyadic behaviors (EDB; Luo, Cartun, \& Snider, 2010). Extradyadic involvement (EDI) is broadly defined as the involvement in sexual and/or emotional EDB with someone other than one's primary partner, while in an exclusive romantic relationship.

According to Luo et al. (2010), most studies do not provide a consistent definition of EDB. The literature has revealed that this definition can comprise very different behaviors (Randall \& Byers, 2003), and thus its operationalization and measurement has been diverse across studies (Blow \& Hartnett, 2005a). Previous research has tended to focus on narrow definitions and most exclusively on extradyadic sexual intercourse (e.g., Mark, Janssen, \& Milhausen, 2011). This restricted definition may produce more reliable estimates; however, it obscures gender-specific patterns in these behaviors (Luo et al., 2010; McAnulty \& Brineman, 2007). Hence, as other types of EDI seem to be also common and are likely to be distressing for those affected, a growing number of studies have considered a wider spectrum of behaviors, both sexual and emotional (e.g., Roscoe, Cavanaugh, \& Kennedy, 1988; Thompson, 1984; Whitty, 2003; Wiederman \& Hurd, 1999). Indeed, despite the low agreement on which behaviors constitute infidelity, there is a consensus that there are two main types of EDI: sexual and emotional (Miller \& Maner, 2009). Moreover, some have advocated the existence of a combined type of infidelity, comprising both sexual and emotional behaviors (e.g., Glass \& Wright, 1985; Thompson, 1984).

Recently, research in this area has begun to consider online EDI (e.g., Henline, Lamke, \& Howard, 2007; Whitty, 2003). Online romantic relationships have been described by individuals as intimate, real, and as important as any face-to-face relationship (Merkle \& Richardson, 2000). 
Although studies have supported the idea that engaging in online sexual conversations and sharing online emotional information are true forms of infidelity (e.g., Docan-Morgan \& Docan, 2007; Underwood \& Findlay, 2004; Whitty, 2003, 2005), according to Shaw (1997), online infidelity is behaviorally different from other types of infidelity. In this context, the associated factors are yet to be well understood.

Although the topic of infidelity in the context of romantic relationships has been widely explored in the literature, data on EDI during dating relationships are still relatively scarce. Studies have traditionally focused on the EDI of married individuals, primarily given the potential negative impact of infidelitous behaviors, such as divorce or relationship dissolution (Harris, 2002). The literature on dating infidelity is also limited due to the difficulties in defining a dating relationship (McAnulty \& Brineman, 2007), mainly because these relationships often lack the recognized commitment to sexual and emotional exclusivity that are reflective in marriage. Nevertheless, there is a strong rationale for studying these extradyadic behaviors during courting, as it is during this time that people may first uphold exclusivity expectations, which may have important implications for later marital adjustment (McAnulty \& Brineman, 2007). Therefore, being able to identify the factors associated with EDI in men and women is of extreme relevance for understanding the occurrence of infidelity (Allen et al., 2005) and identifying at-risk individuals (Whisman, Gordon, \& Chatav, 2007).

Overall, the correlates of EDI may be organized into two major categories: the first involves individual factors, such as demographic characteristics and sexual history; and the second involves relationship factors, such as length and different dimensions of the relationship. Similar to other studies (e.g., Shaw, Rhoades, Allen, Stanley, \& Markman, 2013), we further organized our literature review in the following two categories.

\section{Individual Factors}

Regardless of the type of relationship, gender has been established as the most consistent predictor of EDI (Allen et al., 2005; Blow \& Hartnett, 2005b). Across cultures, it has been shown that during marriage more men than women report EDI (Kontula \& Haavio-Mannila, 1995; Lewin, 2000; Træen \& Stigum, 1998; Wiederman, 1997). In dating relationships, studies also showed higher prevalence rates of EDI for men (Allen \& Baucom, 2004; Martins, Pereira, \& Canavarro, 2014; 
Wiederman \& Hurd, 1999), and a greater inclination of men to engage in extradyadic sex (McAlister, Pachana, \& Jackson, 2005). Regarding online EDI, research has suggested that males are more likely than females to engage in romantic relationships over the internet (Cooper, Delmonic, \& Burg, 2000; Wysocki, 1998) and to engage in online sexual behaviors (Luo et al., 2010; Martins et al., 2014). Yet, recent research suggests that the gap between men and women in rates of EDI is narrowing (Adamopoulou, 2013; Brand, Markey, Mills, \& Hodges, 2007; Havlicek, Husarova, Rezacova, \& Klapilova, 2011; O’Sullivan \& Ronis, 2013), particularly in younger cohorts (Allen et al., 2005; Wysocki \& Childers, 2011). Despite these attenuated differences, gender is considered an important variable (Andrews et al., 2008; Træen \& Martinussen, 2008), not only to understand the prevalence of EDI, but also of its correlates, which may differ as a function of gender (e.g., Havlicek et al., 2011; Mark et al., 2011). Despite findings for gender differences in the prevalence of EDI, we know little whether the correlates of EDI differ between men and women. Thus, in this study, data will be analyzed separately for men and women.

Religion and religiosity have also been linked to infidelity (Atkins, Baucom, \& Jacobson, 2001; Burdette, Ellison, Sherkat, \& Gore, 2007; Forste \& Tanfer, 1996; Mattingly, Wilson, Clark, Bequette, \& Weidler, 2010; Treas \& Giesen, 2000). However, some mixed findings have emerged. Hansen (1987) found a negative association between religiosity and infidelity among women. In contrast, Liu (2000) reported that such an association only existed for men. Similarly, Martins et al. (2014) found that men reporting Catholic religion were more likely to report online EDI. In other studies, religiosity was not related to EDI at all (e.g., Mark et al., 2011; Shaw et al., 2013; Wiederman \& Hurd, 1999).

The association between the level of education and infidelity has been unclear (Allen et al., 2005). Although some studies found an association between higher education and a higher likelihood of infidelity (e.g., Atkins et al., 2001; Træen \& Stigum, 1998; Treas \& Giesen, 2000), others reported no significant associations (e.g., Martins et al., 2014; Shaw et al., 2013; Træen, Holmen, \& Stigum, 2007) or opposing findings (e.g., Choi, Catania, \& Dolcini, 1994). Another relevant variable is the area of residence. Studies have found that residing in large urban areas, as opposed to living in rural areas, is related to a greater likelihood of engaging in EDI (Kontula \& Haavio-Mannila, 1995; Træen 
\& Stigum, 1998; Treas \& Giesen, 2000). This is particularly so due to the fact that larger urban areas may provide more opportunities for engaging in infidelity through increased potential partners and greater anonymity (Allen et al., 2005). However, not all research has supported this association (e.g., Wiederman, 1997).

Several studies have shown that individuals who had experienced sexual intimacy with a greater number of previous partners reported greater EDI (Forste \& Tanfer, 1996; McAlister et al., 2005; Shaw et al., 2013; Træen et al., 2007; Treas \& Giesen, 2000). Regarding the age of the first sexual encounter, research has produced contradictory findings. Træen and Stigum (1998) found that extradyadic relationships decreased with increasing age of first sexual intercourse. Conversely, in the study of McAlister et al. (2005), the age of the first sexual encounter was not significantly associated with extradyadic inclination.

Past history of infidelity has been consistently reported to be a predictor of willingness or actual involvement in EDI (e.g., Adamopoulou, 2013; Banfield \& McCabe, 2001; Buunk \& Bakker, 1995). In turn, although one study noted that a current partner's affair was predictive of infidelity (Whisman et al., 2007), it has yet to be assessed if a prior partner's infidelity is also related to increased likelihood of one engaging in EDI.

Despite the negative attitudes toward extradyadic activities, many individuals actually engage in acts of infidelity (Drigotas, Safstrom, \& Gentilia, 1999). Numerous studies suggest that more permissive attitudes toward infidelity are consistent predictors of personal involvement and willingness for engaging in infidelity at some point in the individual's lives (e.g., Barta \& Kiene, 2005; Glass \& Wright, 1992; Liu, 2000; Treas \& Giesen, 2000; Wiederman, 1997).

\section{Relationship Factors}

Among interpersonal variables, the investment model (Rusbult, 1983) is perhaps most appropriate for prediction of dating infidelity (Drigotas et al., 1999). The investment model sustains that a key force within romantic relationships is commitment, which is a psychological state that globally represents the experience of dependence on a relationship (Rusbult \& Buunk, 1993). In this model, three factors come together to render an individual more or less committed to the relationship: satisfaction, quality of alternatives, and investment. According to this model, individuals who are 
highly satisfied, who have greatly invested in the relationship, and who perceive few appealing alternatives will be highly committed to their romantic relationships (e.g., Impett, Beals, \& Peplau, 2001/2002; Le \& Agnew, 2003; VanderDrift, Lehmiller, \& Kelly, 2012) and thus will be less likely to engage in EDI. Applying this model in a sample of heterosexual university students in a dating relationship, Drigotas et al. (1999) found that lower satisfaction was significantly associated with composite infidelity, physical infidelity, and emotional infidelity measures. Similarly, McAlister et al. (2005) also found that relationship satisfaction was a significant negative predictor of both extradyadic kissing and sex inclination.

Satisfaction with the relationship has received considerable attention in this context (e.g., Banfield \& McCabe, 2001; Glass \& Wright, 1985; Havlicek et al., 2011; Shaw et al., 2013). Young adults have more often designated relationship dissatisfaction as a significant reason for dating infidelity as opposed to either commitment or investment (Roscoe et al., 1988). Nevertheless, Drigotas et al. (1999) reported that both commitment and investment were significant predictors of subsequent infidelity. Banfield and McCabe (2001) also found that women's intentions to engage in extradyadic relationships were higher if they had low commitment to the primary relationship. In contrast, McAlister et al. (2005) found that the quality of alternatives was the strongest predictor of extradyadic sex inclination, as well as kissing inclination, suggesting that it may be a key determinant of individuals' inclination to engage in extradyadic activities.

The association between longer relationships and EDI has been mostly reported in studies with married or cohabiting individuals (Træen et al., 2007; Træen \& Stigum, 1998; Wiederman, 1997). However, it is not clear if this is also true for dating relationships. This finding has been understood in terms of habituation, where the likelihood of infidelity may increase over time due to decreased marital benefits (e.g., reduced frequency of sexual intercourse; Treas \& Giesen, 2000). Yet, it is plausible to expect that if dating relationships become more intimate and committed with time, this could lead to a decreased likelihood of involvement in EDB (McAlister et al., 2005). One study showed that, among women, longer relationships seem to have a greater association with infidelity than shorter relationships. This association was true for married, cohabitating, and dating women (Forste \& Tanfer, 1996). In contrast, Hansen (1987) found that, for men in dating relationships, the 
longer the time of dating the greater likelihood of EDI. In another study with participants in dating relationships, relationship length was not found to be related to EDI (McAlister et al., 2005).

\section{The Present Study}

Although there is considerable research on correlates of EDI among married individuals, less is known about its correlates in dating relationships. Furthermore, despite the extensive literature of gender differences in the prevalence of EDI, little is known about gender-specific correlates of EDI, especially in dating relationships. Therefore, the aim of this study was to examine the gender-specific correlates of face-to-face and online EDI in dating relationships, separately for physical/sexual and emotional behaviors. Based on our literature review, we tested the following hypotheses:

1. Men would report a higher prevalence of EDI than women, and this difference would be greater regarding physical/sexual behaviors (Hypothesis 1 [H1]);

2. The EDI was expected to increase with a prior history of infidelity [H2];

3. The EDI was expected to be related to a greater number of previous sexual partners [H3];

4. The EDI was expected to increase with more favorable attitudes toward infidelity [H4];

5. Regarding the factors of the investment model, it was expected that increased EDI would be associated with lower commitment [H5a], satisfaction [H5b] and investment [H5c] in the relationship, and higher quality of alternatives [H5d].

For the remaining variables (religion, education, area of residence, age at first sexual encounter, and relationship length), given the existence of mixed findings, we did not specify directional hypotheses. Given the lack of studies examining the association between prior partner's infidelity and EDI, no hypothesis was made. Also because of inconsistencies in the operationalization of EDI in past research, no specific hypotheses were defined for each type of EDI.

\section{METHOD}

\section{Participants}

The sample consisted of 793 participants (561 women and 222 men) between the ages of 18 and 51 years $(M=23.41$ years, $S D=3.76)$. The majority of participants were university students (63.2\%), lived in an urban area (73.3\%), and 65.8\% identified themselves as Catholic. All participants were involved in a committed dating, opposite-sex relationship at the time of participation. On 
average, participants had been in their current relationship for 34.65 months ( $S D=26.89$; range, 1 month to 6 years). Both men and women reported initially experiencing sex between the ages of 17-18 years. Male participants were older than female participants, had a lower level of education, were less likely to be students, and were in the current relationship for less time. Also, men were less likely than women to report espousing to the Catholic faith.

Regarding prior history of infidelity, $26.5 \%$ of participants reported to have been unfaithful in a previous relationship, and $37.1 \%$ reported that a partner in a prior relationship had been unfaithful. Women were more likely to report prior infidelity of their previous partner. There were no significant differences found between men and women who reported to have been unfaithful in a previous relationship.

\section{Procedure}

After institutional approval, participants were recruited by two methods: in a community context $(n=178)$, in which participants completed a paper version of the assessment protocol, and through an online survey $(n=605)$, where an online version of the set of assessment measures was made available.

Regarding the first method, participants were consecutively recruited in different outdoor areas of the faculties of the University of Coimbra. The aims of the study as well as the general procedures were presented to the individuals. Confidentiality and anonymity were emphasized to participants on the informed consent, and also verbally by the researcher. In the paper version, and to assure participants of confidentiality, an envelope was provided with the set of questionnaires, with instructions to place the completed questionnaires in an envelope (which was then sealed by the participant). The envelope was not opened until the data collection had been completed. In addition, it was explained to the participants that they would not need to complete the online survey once having answered the paper version. Simultaneously, data were collected through an online survey placed on the website of the University. A web page was also created on the social network Facebook, where the study goals, the inclusion criteria, and the participants' and the researchers' roles were explained. The ethical considerations, particularly the confidentiality and anonymity of the responses, were also on 
the introductory page. A link to the online survey was disclosed on the same page. Participants were not paid or given other incentives to participate in the study.

\section{Measures}

\section{Sociodemographic and Relational Information}

This questionnaire was developed by the researchers and included a first part with sociodemographic information (e.g., gender; age; education; religion; relationship length). A second part covered questions about their past relationship and sexual history (e.g., age of first sexual encounter; number of sexual partners in the past two years). Past history of partner's infidelity and past history of participants' infidelity were also assessed. Regarding partner's infidelity, it was assessed with the question: "Not including your current relationship, and to your knowledge, has a partner ever been unfaithful to you?"; the past history of participant's infidelity was assessed with the question: "Not including your current relationship, have you ever been unfaithful to a partner?"

\section{Extradyadic Behaviors}

Extradyadic involvement was assessed using the Extradyadic Behaviors Inventory (EDBI; Luo et al., 2010). This self-report questionnaire consists of 23 items assessing face-to-face EDB (e.g., "kissing"; "romantic date"; "received oral sex"; "vaginal intercourse") and 13 items assessing online EDB (including internet and phone interactions; e.g., "spent time online with romantic interest"; "shared sexually provocative pictures"; "phone sex"). Participants were asked to report how often they had engaged in each of the listed behaviors while in their current relationship with someone (of the opposite sex) other than their current partner. The instructions of the EDBI were not phrased specifying that these behaviors are infidelity. In this inventory, Wiederman and Hurd's (1999) fivepoint rating scale was adopted by Luo et al. (p. 159): “ $1=$ Did not participate in this behavior because you didn't want to; 2 = Did not participate in this behavior because there was no opportunity; $3=$ Have participated in this behavior only once; $4=$ Have participated in this behavior more than once with the same person; and $5=$ Have participated in this behavior with different people". In this study, we used the two-factor structure of both face-to-face and online EDI previously identified by the authors of the present study, namely: face-to-face physical/sexual EDI, face-to-face emotional EDI, 
online sexual EDI and online emotional EDI. Cronbach's alpha ranged between .73 (online sexual EDI - women) and .98 (face-to-face physical/sexual EDI - men).

\section{Attitudes Toward Infidelity}

Attitudes toward infidelity were assessed with the Attitudes toward Infidelity Scale (ATIS; Whatley, 2012). This self-report scale comprises 12 items assessing attitudes toward infidelity, which were rated on a seven-point Likert scale $(1=$ Strongly agree to $7=$ Strongly disagree $)$, with 1 reflecting the least acceptance of infidelity and 7 the greatest acceptance of infidelity. Possible total scores of this scale range from 12 to 84 , with higher scores representing greater acceptance of infidelity. The alpha reliability for men and women was .72 and .70 , respectively.

\section{Investment Model}

The four constructs of the investment model were assessed with the Investment Model Scale (IMS; Rusbult, Martz, \& Agnew, 1998). According to the IMS instructions, participants are required to be involved in a romantic relationship in order to complete this measure. The Satisfaction, Quality of alternatives, and Investment subscales were measured by two types of items, described as facet items and global items. Facet items are specific examples of the construct, designed to prepare the participant to answer the global items that provide a more general measure of the construct items (e.g., Satisfaction subscale: "My partner fulfills my need for companionship" [facet item]; "Our relationship makes me very happy" [global item]). It is argued that facet items increase the reliability and validity of the measure. The Commitment subscale uses only global items (e.g., "I am oriented towards the long term future of our relationship"). Facet items were answered on a four-point response scale between 1 (Completely disagree) and 4 (Completely agree). The global items were answered on a 9point response scale ranging from 0 (Do not agree at all) to 8 (Completely agree). Scores were obtained by adding the ratings for the global items, with high scores representing higher levels of the respective concept. The alpha reliabilities in this sample for the IMS subscales ranged from .77 (investment for women) to .91 (satisfaction for men).

\section{RESULTS}

\section{Gender Differences on the Prevalence of Extradyadic Involvement}


A $\chi^{2}$ analysis was conducted to test the hypothesis that the prevalence of EDI was significantly higher among men than women [H1]. Effect sizes are presented for all comparisons (small effects: Cramer's $V \geq .01$; medium effects: Cramer's $V \geq .03$; large effects: Cramer's $V \geq .05$ ) (Cohen, 1992). No significant differences were found between men and women in the overall EDB measure: $36.9 \%$ of men and $42.2 \%$ of women reported that they had never engaged in any of the 23 face-to-face EDB assessed by the EDBI, $\chi_{(1)}^{2}=1.86, n s$, Cramer's $V=.05$. In addition, $52.7 \%$ and $59.4 \%$ of men and women, respectively, reported that they had never engaged in any of the 13 online EDB during the current relationship, $\chi_{(1)}^{2}=2.88, n s$, Cramer's $V=.06$. Regarding the different types of EDI, men were more likely to report engagement in both face-to-face physical/sexual EDI and online sexual EDI. No significant differences were found regarding emotional EDI. Table 2 shows the proportion of participants engaging in the different types of EDI.

\section{Correlates of Face-to-Face Physical/Sexual EDI}

To address hypotheses $2-5$, a set of logistic regression analyses (separately by gender) were conducted, in which the involvement in EDB was coded as 0 (never engaged in EDB) and 1 (engaged at least in one $\mathrm{EDB})$. Variables with a $p$ value $<.10$ in the univariate analysis were included in the multivariate logistic regression model and displayed as odds ratios (OR) with $95 \%$ confidence intervals $(\mathrm{CI})$.

In the univariate analysis, for both men and women, prior history of infidelity [H2], more favorable attitudes toward infidelity [H4], lower commitment [H5a] and satisfaction [H5b], and higher scores on quality of alternatives $[\mathrm{H} 5 \mathrm{c}]$ were significantly associated with engagement in faceto-face physical/sexual EDI. In the multivariate model, men with prior history of infidelity [H2] and more favorable attitudes toward infidelity [H4] were more likely to engage in face-to-face physical/ sexual EDI. Among women, those with prior history of infidelity [H2], more favorable attitudes toward infidelity [H4], and reporting lower commitment in the current relationship [H5a] were more likely to engage in face-to-face physical/sexual EDI. The results are shown in Table 3.

\section{Correlates of Face-to-Face Emotional EDI}

Among men, in the univariate logistic regression analysis, more positive attitudes toward infidelity [H4] and higher scores on quality of alternatives [H5d], and lower satisfaction [H5b] and 
commitment $[\mathrm{H} 5 \mathrm{a}]$ were significantly associated with engagement in face-to-face emotional EDI. In the multivariate logistic regression analysis, only men reporting higher satisfaction with their relationship [H5b] were less likely to engage in face-to-face emotional $\mathrm{EDI}, \mathrm{OR}=0.55 ; 95 \% \mathrm{CI}$ : $0.32-0.94$.

Among women, several factors were associated with engagement in face-to-face emotional EDI, including longer relationship length, younger age at the first sexual encounter, prior history of infidelity [H2], infidelity of a partner in a previous relationship, positive attitudes toward infidelity [H4], lower commitment [H5a] and satisfaction [H5b] in the current relationship, and higher quality of alternatives [H5d]. In the multivariate model, women with a longer relationship, with younger age at the first sexual encounter, reporting infidelity of a partner in a previous relationship, lower satisfaction [H5b] and higher quality of alternatives [H5d] were more likely to engage in face-to-face emotional EDI (Table 4).

\section{Correlates of Online Sexual EDI}

The logistic regression models regarding the correlates of online sexual EDI are shown in Table 5. Among men, in the univariate analysis, prior history of infidelity [H2], positive attitudes toward infidelity [H4], and all investment model variables [H5] were significantly associated with online sexual EDI. In the multivariate model, only a positive attitude toward infidelity [H4] and lower satisfaction in the current relationship [H5b] were significantly related to a higher probability of engaging in online sexual EDI.

For women, in the univariate logistic regression analysis, higher education, a higher number of sexual partners in the last two years [H3], prior history of infidelity [H2], favorable attitudes toward infidelity [H4], lower commitment [H5a] and higher quality of alternatives [H5d] were significantly associated with online sexual EDI. In the multivariate model, only education stood out as a significant correlate: women who had higher education were 2.77 times more likely to report engagement in online sexual EDI (Table 5).

\section{Correlates of Online Emotional EDI}

As regards online emotional EDI, men with a prior history of infidelity [H2], more favorable attitudes toward infidelity [H4], lower commitment [H5a] and satisfaction [H5b] in the current 
relationship and higher quality of alternatives [H5d] were more likely to report engagement in online emotional EDI. In the multivariate model, only lower satisfaction with the relationship [H5b] was significantly associated with online emotional EDI (Table 6).

Among women, similar to the findings that have been found regarding face-to-face emotional EDI, prior history of infidelity [H2], infidelity of a partner in a previous relationship, a favorable attitude toward infidelity [H4], lower satisfaction [H5b] and commitment [H5a], and higher quality of alternatives [H5d] were significantly related to online emotional EDI. In the multivariate logistic regression model, women with prior history of infidelity [H2], and those reporting infidelity of a partner in a prior relationship, lower satisfaction in the current relationship [H5b] and higher quality of alternatives [H5d] were more likely to engage in online emotional EDI (Table 6).

\section{DISCUSSION}

The present study examined the gender-specific correlates of EDI in dating relationships, extending prior research examining the factors associated with face-to-face EDI, and being the first to analyze the correlates of face-to-face and online EDI, separately for physical/sexual and emotional behaviors. Our findings corroborate the earlier literature in terms of prevalence rates of EDI in dating relationships. They confirm that more men than women report experience in EDI, and highlight the importance of prior history of infidelity, attitudes toward infidelity and relationship factors (particularly those factors underscored by the investment model) as correlates of both face-to-face and online EDI. In addition, the results of this study indicated that EDI, for both men and women, seemed to differ more by type (i.e., sexual/emotional) than by modality (i.e., face-to-face/online). Finally, another relevant contribution concerns the existence of gender-specific patterns in these associations.

In this study, the prevalence rates of EDI are similar to those earlier reported in the context of dating relationships (e.g., Hansen, 1987), but relatively lower, compared to those found by Luo et al. (2010), in which the same measure has been used. These rates are higher than those reported among married or cohabiting individuals (Træen \& Martinussen, 2008), which may reflect the lower commitment to sexual and emotional exclusivity that typifies dating relationships (McAnulty \& Brineman, 2007). Regarding gender differences, although men reported greater involvement in faceto-face EDB and online EDB than women, there were no significant gender differences in the overall 
EDB measure. This is in line with prior findings (Brand et al., 2007), and reinforce the literature suggesting that the differences between men and women are lessening in younger cohorts (Allen et al., 2005; Wysocki \& Childers, 2011). This may be due to the diversity and specificity of behaviors included in our study. However, it is also plausible that these findings may reflect more liberal attitudes towards sexuality, resulting from recent social changes, which, in turn, can increase the willingness to openly report about one's sexuality (Brand et al., 2007; Havlicek et al., 2011).

Despite the lack of differences in overall EDI, when comparing emotional vs. sexual types of EDI, more men than women report engaging in sexual behaviors, in both face-to-face and online modalities, which supports our first hypothesis [H1]. This is consistent with research suggesting that men and women engage in different types of EDI, principally studies showing that men were more likely to engage in sexual EDI, whereas women's EDI was more often linked to emotional connection (Glass \& Wright, 1985; McAlister et al., 2005; Thompson, 1984). A possible explanation may relate to the sociocultural based theories that suggest that men are often reinforced to be sexual permissive (Harvey \& Hackathorn, 2011), while women are expected to relate more strongly sex with love (Kelly \& Bazzini, 2001). Supporting the results of Luo et al. (2010), men were also more likely than women to engage in online sexual EDI. The anonymous and easy-to-access nature of the Internet may help to explain this result. Because there is evidence that men use online sexual behaviors as a convenient escape from life's problems (Young, Griffin-Shelley, Cooper, O’Mara, \& Buchanan, 2000), it would be relevant to address in future research why men are also more likely than women to engage in online EDI. In this study, there were no gender differences concerning the engagement in emotional EDI, as previously reported (Wiederman \& Hurd, 1999). As suggested by Luo et al. (2010), for some individuals emotional EDI may serve as an opportunity to engage in future sexual behaviors. However, we also admit that as sexuality has been changing for women in recent years, it is also likely that establishing emotional bonds with someone else before a sexual interaction is becoming more important for men.

In line with past research (Adamopoulou, 2013; Banfield \& McCabe, 2001), men and women with a prior history of infidelity were more likely to engage in EDI, which supports our second hypothesis [H2]. As stated by McAnulty and Brineman (2007), this repetitive pattern may relate to the 
low commitment to a relationship or a threshold effect, that is, once an individual has engaged in extradyadic behaviors, any future transgression seems less important. Partially supporting our third hypothesis [H3], a higher number of sexual partners in the past two years was related to the engagement in sexual EDI, but only for women. Because the existing studies did not examine this as a function of gender, it is probable that this association may be different for men and women, although this needs to be further explored. As predicted in the fourth hypothesis [H4], regardless of gender, positive attitudes toward infidelity were consistently associated with EDI, as one would expect from literature on attitudes predicting behavior (Eagly \& Chaiken, 1998). Multivariate analyses indicated that these attitudes were linked specifically with physical/sexual EDI, which seem to suggest alternative explanatory mechanisms in this relation. Future research should examine potential mediators, such as personality characteristics, that may help clarify this association.

The hypotheses related to the constructs of the investment model were only partially supported. Corroborating prior studies (e.g., Drigotas et al., 1999; Glass \& Wright, 1985; McAlister et al., 2005; Shaw et al., 2013), for both men and women, lower satisfaction was significantly related to greater engagement in physical/sexual and emotional EDI [H5b]. Contrary to the notion that the link between satisfaction and EDI was greater for women than for men (Glass \& Wright, 1985), we found that satisfaction was a key correlate also for males, being the only dimension of the investment model to be significantly associated with face-to-face and online emotional EDI in the multivariate models (for every one unit increase in satisfaction, men were $45 \%$ to $73 \%$ less likely to have engaged in EDB). This variable was particularly significant for engaging in emotional EDI, which is consistent with the research showing that one motivation for EDI is to fulfill unmet intimacy needs (Allen \& Rhoades, 2008). Regarding online EDI, our findings are partially in line with the suggestion that men and women who felt sexually unsatisfied in their relationships view online interactions as a means to feel understood and where they were more able to share personal feelings (Underwood \& Findlay, 2004). The internet features seem to be a relevant venue to develop emotional intimacy, which may not be perceived as missing in the primary relationship (Whitty, 2003), but that probably may reflect the individuals' relationship dissatisfaction. 
In a recent study (Shaw et al., 2013), it has been shown that lower commitment predicted future extradyadic sexual involvement. Consistent with this result and partially supporting our hypothesis [H5a], a lower level of commitment was related to face-to-face physical/sexual EDI, but only for females. Although we have not found a clear rationale from prior evidence for why women with lower levels of commitment are more likely to engage in sexual EDI, this result may be related to the assumption that the lack of commitment makes an individual less concerned about the feelings of the primary partner, and thus more inclined to engage in sexual EDI (Buunk \& Bakker, 1997). Further, it is likely that lower commitment may reflect women's relationship dissatisfaction, and thus they may be searching for new partners to substitute the current one. This study also found that only women reporting higher quality of alternatives were more likely to engage in both face-to-face and online emotional EDI, thus partially supporting our hypothesis [H5d]. These findings may be understood in the context of the evolutionary theory (Trivers, 1972), which asserts that females are more likely than males to look for partners who are able to provide them with the resources they need to raise the children, and are also more likely to seek partners who are able to establish and maintain deep emotional attachments with them (Luo et al., 2010). Thus, it is plausible that women use emotional EDI as a way to find a new partner without first giving up the security and protection existing in or provided by the primary relationship (Shaw et al., 2013).

Other variables, especially those related to sexual and relational history, are also relevant correlates of EDI, mainly for females. One interesting finding was that women who reported infidelity of a partner in a prior relationship were more likely to engage in emotional EDI, both face-to-face and online. It has been suggested that having an unfaithful partner or being suspicious has been related to extradyadic sexual involvement (Shaw et al., 2013; Whisman et al., 2007). It is likely that in part this result may reflect the women's loss of trust in romantic relationships, and thus, women may engage in emotional EDI as a way to test alternatives or a gateway to future relationships. The length of the primary relationship was associated with an increased likelihood of women engaging in emotional EDI. This may be related to the characteristics of the sample (on average, women have longer relationships than men), but can also be understood in terms of the aforesaid habituation hypothesis (Treas \& Giesen, 2000). As this result was non-significant in most analyses, we also admit that the 
relationship length may be of minor importance in dating relationships. In this study, despite the varying associations between education and EDI, women with higher education were about three times more likely to engage in online sexual EDI. This is similar to the finding showing that dating women with higher education were more likely to have secondary sex partners (Forste \& Tanfer, 1996), as well as the evidence that those who become involved in romantic online relationships tend to be tertiary-educated (Underwood \& Findlay, 2004).

\section{Strengths, Limitations, and Future Directions}

The importance of these findings is enhanced by several strengths. Since research in the context of dating relationships is rather recent and limited, this study makes an important input to the literature, by providing a multi-dimensional and comprehensive approach of EDI. Another contribution is the inclusion of the online sexual and emotional interactions. As well, as EDI during dating may have implications for later married relationships, assessing their correlates can represent earlier opportunities to evaluate potential risk factors for the stability of relationships and to intervene (Shaw et al., 2013). Although dating couples are not the usual target of psychological interventions, this knowledge may also lead to applications in the field of couple and family therapy (McAnulty \& Brineman, 2007; Shaw et al., 2013).

It should be noted that this study overcomes some of the limitations of prior research in this area. An important input relates to the conceptualization and assessment of EDI. The use of a measure that comprises behavioral indicators highly specific and unequivocal may have reduced the ambiguity and the susceptibility of interpretation by the participants. However, without knowledge of the specific relationship norms, some of these EDB could be behaviors that are allowed within the relationship. As individuals in open relationships were excluded, and all participants explicitly indicated that they were in an exclusive relationship, we believe these findings are more reliable. Although the overrepresentation of women has been problematic in most studies, the option of examining the correlates of EDI as a function of gender is also an important contribution. The data collection mostly through an online survey is a further strength, mostly because research suggests that social desirability is minimized in online studies, especially when addressing topics of sensitive nature, compared to the traditional use of pen and paper questionnaires (Turner et al., 1998). 
Although the contributions of this study are noteworthy, some limitations should be acknowledged. Due to the cross-sectional design we cannot draw causal relations between the variables. Since our data was drawn from a community sample (mostly comprising university students) recruited by convenience, our findings may not be possible to generalize to other populations. This study relied on self-reported data, which along with the sensitive nature of this topic, may be prone to social desirability biases. Overall, in this study, participants completing the online survey reported higher prevalence rates of EDI, which is in line with prior studies indicating that the method of assessment has a great impact on the responses (Whisman \& Snyder, 2007). However, as stated, we believe that the data collection principally through an online survey may have allowed us to achieve more reliable results.

The research of correlates of EDI is growing. However, further studies separating analyses as a function of gender, including both types and modalities of EDI and other relationship types are still important. As the Internet increases as a popular means of communication, it is important to start inquiring how the use of this technology influences romantic relationships (Whitty, 2003). The longitudinal assessment of patterns of EDI over time is also needed. Finally, it would be crucial to conduct these analyses among couples. Future research would benefit from close tracking of couples over time to comprehend the processes and/or mechanisms underlying the transition from trust and fidelity to engaging in an extradyadic relationship. 


\section{REFERENCES}

Adamopoulou, E. (2013). New facts on infidelity. Economic Letters, 121, 458-462.

doi:10.1016/j.econlet.2013.09.025

Allen, E. S., Atkins, D., Baucom, D., Snyder, D., Gordon, K., \& Glass, S. (2005). Intrapersonal, interpersonal, and contextual factors in engaging in and responding to extramarital involvement. Clinical Psychology: Science and Practice, 12, 101-130. doi:10.1093/clipsy/bpi014

Allen, E. S., \& Baucom, D. (2004). Adult attachment and patterns of extradyadic involvement. Family Process, 43, 467-488. doi:10.1111/j.1545-5300.2004.00035.x

Allen, E. S., \& Rhoades, G. K. (2008). Not all affairs are created equal: Emotional involvement with an extradyadic partner. Journal of Sex \& Marital Therapy, 34, 51-65. doi:10.1080/00926230701620878

Andrews, P. W., Gangestad, S. W., Miller, G. F., Haselton, M. G., Thornhill, R., \& Neale, M. C. (2008). Sex differences in detecting sexual infidelity. Human Nature, 19, 347-373. doi:10.1007/s12110-008-9051-3

Atkins, D. C., Baucom, D., \& Jacobson, N. (2001). Understanding infidelity: Correlates in a national random sample. Journal of Family Psychology, 15, 735-749. doi:10.1037//0893-3200.15.4.735

Banfield, S., \& McCabe, M. (2001). Extra relationship involvement among women: Are they different from men? Archives of Sexual Behavior, 30, 119-142. doi:10.1023/A:1002773100507

Barta, W., \& Kiene, S. (2005). Motivations for infidelity in heterosexual dating couples: The roles of gender, personality differences, and sociosexual orientation. Journal of Social and Personal Relationships, 22, 339-360. doi:10.1177/0265407505052440

Blow, A., \& Hartnett, K. (2005a). Infidelity in committed relationships I: A methodological review. Journal of Marital and Family Therapy, 31, 183-216. doi:10.1111/j.1752-0606.2005.tb01555.x

Blow, A., \& Hartnett, K. (2005b). Infidelity in committed relationships II: A substantive review. Journal of Marital and Family Therapy, 31, 217-233. doi:10.1111/j.1752-0606.2005.tb01556.x 
Boekhout, B. A., Hendrick, S. S., \& Hendrick, C. (2003). Exploring infidelity: Developing the Relationship Issues Scale. Journal of Loss and Trauma, 8, 283-306. doi:10.1080/15325020305882

Brand, R., Markey, C., Mills, A., \& Hodges, S. (2007). Sex differences in self-reported infidelity and its correlates. Sex Roles, 57, 101-109. doi:10.1007/s11199-007-9221-5

Burdette, A. M., Ellison, C. G., Sherkat, D. E., \& Gore, K. A. (2007). Are there religious variations in marital infidelity? Journal of Family Issues, 28, 1553-1581. doi:10.1177/0192513X07304269

Buunk, B. P., \& Bakker, A. B. (1995). Extradyadic sex: The role of descriptive and injunctive norms. Journal of Sex Research, 32, 313-318. doi:10.1080/00224499509551804

Buunk, B. P., \& Bakker, A. B. (1997). Commitment to the relationship, extradyadic sex, and AIDS preventive behavior. Journal of Applied Social Psychology, 27, 1241-1257. doi:10.1111/j.15591816.1997.tb01804.x

Choi, K., Catania, J. A., \& Dolcini, M. M. (1994). Extramarital sex and HIV risk behavior among US adults: Results from the National AIDS Behavioral Survey. American Journal of Public Health, 84, 2003-2007. doi:10.2105/AJPH.84.12.2003

Cohen, J. (1992). A power primer. Psychological Bulletin, 112, 155-159. doi:10.1037/00332909.112.1.155

Cooper, A., Delmonico, D. L., \& Burg, R. (2000). Cybersex users, abusers, and compulsives: New findings and implications. Sexual Addiction \& Compulsivity, 7, 5-29. doi:10.1080/10720160008400205

DeGenova, M. K., \& Rice, F. P. (2005). Intimate relationships, marriages, and families ( $6^{\text {th }}$ ed.). Boston: McGraw Hill.

de Roda, A. B. L., Martínez-Íñigo, D., de Paúl, P., \& Yela, C. (1999). Romantic beliefs and myths in Spain. Spanish Journal of Psychology, 2, 64-73.

Docan-Morgan, T., \& Docan, C. A. (2007). Internet infidelity: Double standards and the differing views of women and men. Communication Quarterly, 55, 317-342. doi:10.1080/01463370701492519 
Drigotas, S. M., Safstrom, A., \& Gentilia, T. (1999). An investment model prediction of dating infidelity. Journal of Personality and Social Psychology, 77, 509-524. doi:10.1037/00223514.77.3.509

Eagly, A. H., \& Chaiken, S. (1998). Attitudes structure and function. In D. T. Gilbert, S. Fiske, \& G. Lindzey (Eds.), The handbook of social psychology (Vol. I, pp. 269-322). New York: McGrawHill.

Forste, R., \& Tanfer, K. (1996). Sexual exclusivity among dating, cohabiting, and married women. Journal of Marriage and Family, 58, 33-47.

Glass, S. P., \& Wright, T. L. (1985). Sex differences in type of extramarital involvement and marital dissatisfaction. Sex Roles, 12, 1101-1120. doi:10.1007/BF00288108

Glass, S. P., \& Wright, T. L. (1992). Justifications for extramarital relationships: The association between attitudes, behaviors, and gender. Journal of Sex Research, 29, 361-387. doi:10.1080/00224499209551654

Haavio-Mannila, E., \& Kontula, O. (2003). Single and double sexual standards in Finland, Estonia, and St. Petersburg. Journal of Sex Research, 40, 36-49. doi:10.1080/00224490309552165

Hansen, G. L. (1987). Extradyadic relations during courtship. Journal of Sex Research, 23, 382-390. doi:10.1080/00224498709551376

Harvey, R., \& Hackathorn, J. (2011) Sexual double standards: Bias in perceptions of cyber-infidelity. Sexuality \& Culture, 15, 100-113. doi:10.1007/s12119-010-9082-х

Harris, C. R. (2002). Sexual and romantic jealousy in heterosexual and homosexual adults. Psychological Science, 13, 7-12. doi:10.1111/1467-9280.00402

Havlicek, J., Husarova, B., Rezacova, V., \& Klapilova, K. (2011). Correlates of extra-dyadic sex in Czech heterosexual couples: Does sexual behavior of parents matter? Archives of Sexual Behavior, 40, 1153-1163. doi:10.1007/s10508-011-9869-3

Henline, B. H., Lamke, L. K., \& Howard, M. D. (2007). Exploring perceptions of online infidelity. Personal Relationships, 14, 113-128. doi:10.1111/j.1475-6811.2006.00144.x 
Impett, E. A., Beals, K. P., \& Peplau, L. A. (2001/2002). Testing the investment model of relationship commitment and stability in a longitudinal study of married couples. Current Psychology, 20, 312-326. doi:10.1007/s12144-001-1014-3

Kelly, J., \& Bazzini, D. G. (2001). Gender, sexual experience, and the sexual double standard: Evaluations of female contraceptive behavior. Sex Roles, 45, 785-799. doi:10.1023/A:1015640419862

Kontula, O., \& Haavio-Mannila, E. (1995). Sexual pleasures: Enhancement of sex life in Finland, 1971-1992. Brookfield, VT: Dartmouth Publishing Company.

Le, B., \& Agnew, C. R. (2003). Commitment and its theorized determinants: A meta-analysis of the investment model. Personal Relationships, 10, 37-57. doi:10.1111/1475-6811.00035

Lewin, B. (2000). Sexual intercourse and partners. In B. Lewin (Ed.), Sex in Sweden: On the Swedish sexual life (pp. 76-79). Stockholm: National Institute of Public Health.

Liu, C. (2000). A theory of marital sexual life. Journal of Marriage and Family, 62, 363-374. doi:10.1111/j.1741-3737.2000.00363.x

Luo, S., Cartun, M., \& Snider, A. (2010). Assessing extradyadic behavior: A review, a new measure, and two new models. Personality and Individual Differences, 49, 155-163. doi:10.1016/j.paid.2010.03.033

Mark, K., Janssen, E., \& Milhausen, R. (2011). Infidelity in heterosexual couples: Demographic, interpersonal, and personality-related predictors of extradyadic sex. Archives of Sexual Behavior, 40, 971-982. doi:10.1007/s10508-011-9771-z

Martins, A., Pereira, M., \& Canavarro, M. C. (2014). Comportamentos extra-diádicos nas relações de namoro: Diferenças de sexo na prevalência e correlatos [Extradyadic behaviors in dating relationships: Sex differences in prevalence and correlates]. Análise Psicológica, 32, 45-62. doi:10.14417/ap.740

Mattingly, B. A., Wilson, K., Clark, E. M., Bequette, A. W., \& Weidler, D. J. (2010). Foggy faithfulness: Relationship quality, religiosity, and the Perceptions of Dating Infidelity Scale in an adult sample. Journal of Family Issues, 31, 1465-1480. doi:10.1177/0192513X10362348 
McAlister, A., Pachana, N., \& Jackson, C. (2005). Predictors of young dating adults' inclination to engage in extradyadic sexual activities: A multi-perspective study. British Journal of Psychology, 96, 331-350. doi:10.1348/000712605X47936

McAnulty, R., \& Brineman, J. (2007). Infidelity in dating relationships. Annual Review of Sex Research, 18, 94-114. doi:10.1080/10532528.2007.10559848

Merkle, E., \& Richardson, R. (2000). Digital dating and virtual relating: Conceptualizing computer mediated romantic relationships. Family Relations, 49, 187-192. doi:10.1111/j.17413729.2000.00187.x

Miller, S., \& Maner, J. (2009). Sex differences in response to sexual versus emotional infidelity: The moderating role of individual differences. Personality and Individual Differences, 46, 287-291. doi:10.1016/j.paid.2008.10.013

O’Sullivan, L. F., \& Ronis, S. T. (2013). Virtual cheating hearts: Extradyadic and poaching interactions among adolescents with links to online sexual activities. Canadian Journal of Behavioural Science, 45, 175-184. doi:10.1037/a0031683

Randall, H. E., \& Byers, E. S. (2003). What is sex? Students' definitions of having sex, sexual partner, and unfaithful sexual behaviour. Canadian Journal of Human Sexuality, 12, 87-96.

Roscoe, B., Cavanaugh, L., \& Kennedy, D. (1988). Dating infidelity: Behaviors, reasons and consequences. Adolescence, 23, 35-43.

Rusbult, C. E. (1983). A longitudinal test of the investment model: The development (and deterioration) of satisfaction and commitment in heterosexual involvement. Journal of Personality and Social Psychology, 45, 101-117. doi:10.1037/0022-3514.45.1.101

Rusbult, C. E., \& Buunk, B. P. (1993). Commitment processes in close relationships: An interdependence analysis. Journal of Social and Personal Relationships, 10, 175-204. doi:10.1177/026540759301000202

Rusbult, C. E., Martz, J. M., \& Agnew, C. R. (1998). The Investment Model Scale: Measuring commitment level, satisfaction level, quality of alternatives, and investment size. Personal Relationships, 5, 357-391. doi:10.1111/j.1475-6811.1998.tb00177.x 
Shaw, A. M., Rhoades, G. K., Allen, E. S., Stanley, S .M., \& Markman, H. J. (2013). Predictors of extradyadic sexual involvement in unmarried opposite-sex relationships. Journal of Sex Research, 50, 598-610. doi:10.1080/00224499.2012.666816

Shaw, J. (1997). Treatment rationale for Internet infidelity. Journal of Sex Education and Therapy, 22, 29-34.

Thompson, A. P. (1984). Emotional and sexual components of extramarital relations. Journal of Marriage and Family, 46, 35-42.

Træen, B., Holmen, K., \& Stigum, H. (2007). Extradyadic sexual relationships in Norway. Archives of Sexual Behavior, 36, 55-65. doi:10.1007/s10508-006-9080-0

Træen, B., \& Martinussen, M. (2008). Extradyadic activity in a random sample of Norwegian couples. Journal of Sex Research, 45, 319-328. doi:10.1080/00224490802398324

Træen, B., \& Stigum, H. (1998). Parallel sexual relationships in the Norwegian context. Journal of Community \& Applied Social Psychology, 8, 41-56.

Treas, J., \& Giesen, D. (2000). Sexual infidelity among married and cohabiting Americans. Journal of Marriage and Family, 62, 48-60. doi:10.1111/j.1741-3737.2000.00048.x

Trivers, R. (1972). Parental investment and sexual selection. In B. Campbell (Ed.), Sexual selection and the descent of man: 1871-1971 (pp. 136-179). Chicago: Aldine-Atherton.

Turner, C. F., Ku, L., Rogers, S. M., Lindberg, L. D., Pleck, J. H., \& Stonenstein, F. L. (1998). Adolescent sexual behavior, drug use, and violence: Increased reporting with computer survey technology. Science, 280, 867-873. doi:10.1126/science.280.5365.867

Underwood, H., \& Findlay, B. (2004). Internet relationships and their impact on primary relationships. Behaviour Change, 21, 127-140. doi:10.1375/bech.21.2.127.55422

VanderDrift, L. E., Lehmiller, J. J., \& Kelly, J. R. (2012). Commitment in friends with benefits relationships: Implications for relational and safe-sex outcomes. Personal Relationships, 19, 113. doi:10.1111/j.1475-6811.2010.01324.x

Whatley, M. A. (2012). Attitudes toward infidelity scale. In D. Knox, \& C. Schacht (Eds.), Choices in relationships: An introduction marriage and the family (11 $1^{\text {th }}$ ed., p. 415). Belmont, CA: Thompson Wadsworth Publishing. 
Whisman, M. A., Gordon, K. C., \& Chatav, Y. (2007). Predicting sexual infidelity in a populationbased sample of married individuals. Journal of Family Psychology, 21, 320-324. doi:10.1037/0893-3200.21.2.320

Whisman, M. A., \& Snyder, D. K. (2007). Sexual infidelity in a national survey of American women: Differences in prevalence and correlates as a function of method of assessment. Journal of Family Psychology, 21, 147-154. doi:10.1037/0893-3200.21.2.147

Whitty, M. (2003). Pushing the wrong buttons: Men's and women's attitudes toward online and offline infidelity. CyberPsychology \& Behavior, 6, 569-579. doi:10.1089/109493103322725342

Whitty, M. T. (2005). The realness of cybercheating: Men's and women's representations of unfaithful Internet relationships. Social Science Computer Review, 23, 57-67. doi:10.1177/0894439304271536

Wiederman, M. W. (1997). Extramarital sex: Prevalence and correlates in a national survey. Journal of Sex Research, 34, 167-174. doi:10.1080/00224499709551881

Wiederman, M. W., \& Hurd, C. (1999). Extradyadic involvement during dating. Journal of Social and Personal Relationships, 16, 265-274. doi:10.1177/0265407599162008

Wysocki, D. K. (1998). Let your fingers do the talking: Sex on an adult chat-line. Sexualities, 1, 425452. doi:10.1177/136346098001004003

Wysocki, D. K., \& Childers, C. D. (2011). "Let my fingers do the talking”: Sexting and infidelity in cyberspace. Sexuality \& Culture, 15, 217-239. doi:10.1007/s12119-011-9091-4

Young, K. S., Griffin-Shelley, E., Cooper, A, O’Mara, J., Buchanan, J. (2000). Online infidelity: A new dimension in couple relationships with implications for evaluation and treatment. Sexual Addiction \& Compulsivity, 7, 59-74. doi:10.1080/10720160008400207 
Table 1

Characteristics of the study sample $(N=783)$

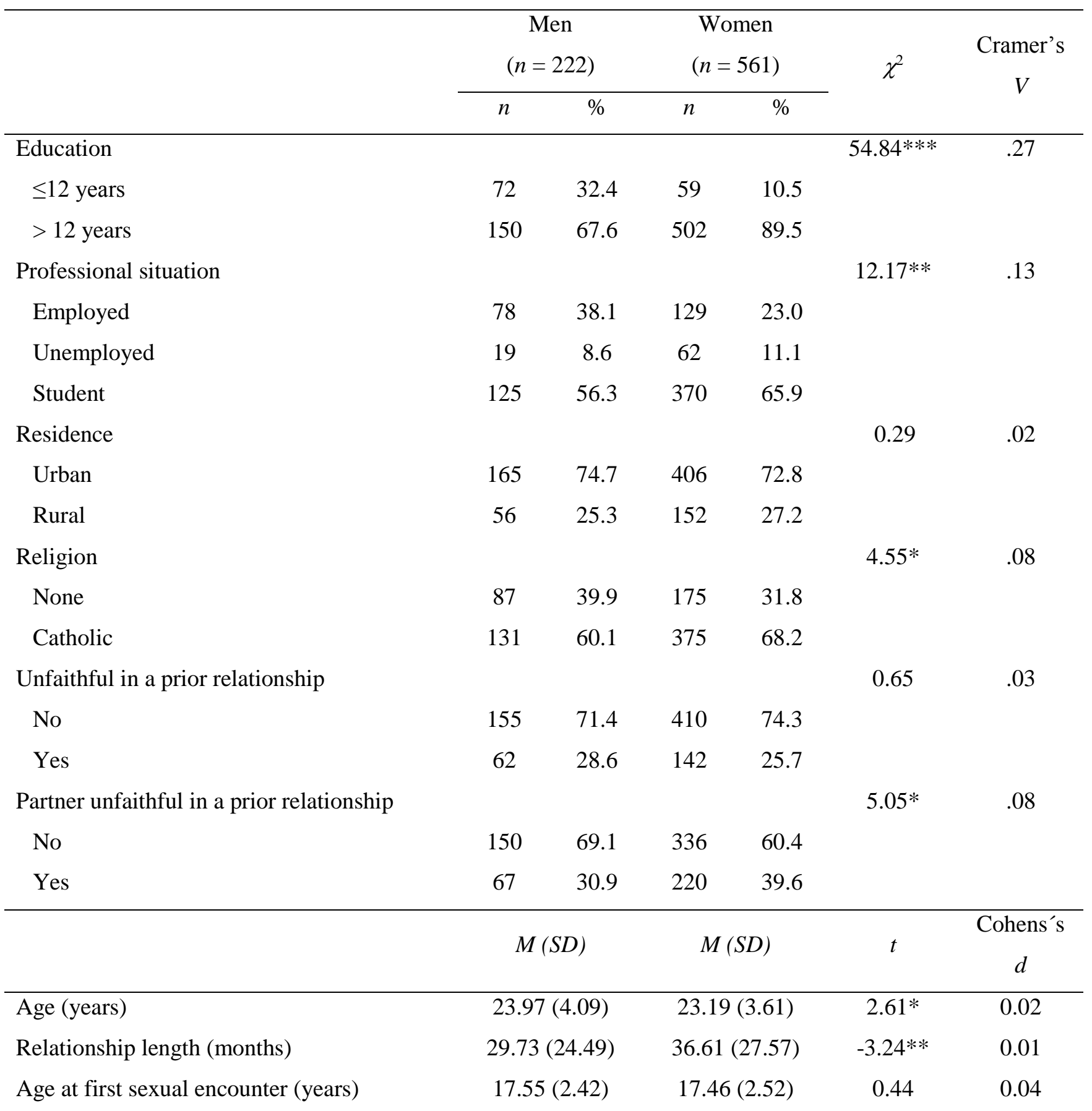

Note: The $n$ s of variables do not add up to 793 due to missing values. For the demographic and variables related to sexual history, the number of missing responses varied from 0 to 15 .

$* p<.05 ; * * p<.01 ; * * * p<.001$ 
Table 2

Gender differences extradyadic involvement $(N=783)$

\begin{tabular}{|c|c|c|c|c|c|c|}
\hline & \multicolumn{2}{|c|}{$\operatorname{Men}(n=222)$} & \multicolumn{2}{|c|}{ Women $(n=561)$} & \multirow{2}{*}{$\chi^{2}$} & \multirow{2}{*}{$\begin{array}{c}\text { Cramer's } \\
V\end{array}$} \\
\hline & $n$ & $\%$ & $n$ & $\%$ & & \\
\hline Face-to-face physical/sexual EDI & & & & & $6.83 * *$ & .09 \\
\hline No & 170 & 76.6 & 474 & 84.5 & & \\
\hline Yes & 52 & 23.4 & 87 & 15.5 & & \\
\hline Face-to-face emotional EDI & & & & & 1.91 & .05 \\
\hline No & 83 & 37.4 & 240 & 42.8 & & \\
\hline Yes & 139 & 62.6 & 321 & 57.2 & & \\
\hline Online sexual EDI & & & & & $25.64 * * *$ & .18 \\
\hline No & 188 & 84.7 & 535 & 94.7 & & \\
\hline Yes & 34 & 15.3 & 26 & 4.6 & & \\
\hline Online emotional EDI & & & & & 2.51 & .06 \\
\hline No & 118 & 53.2 & 333 & 59.4 & & \\
\hline Yes & 104 & 46.8 & 228 & 40.6 & & \\
\hline
\end{tabular}


Table 3

Univariate and multivariate logistic regression analysis of correlates of face-to-face physical/sexual EDI among men and women

\begin{tabular}{|c|c|c|c|c|c|c|c|c|}
\hline \multirow{3}{*}{ Variables } & \multicolumn{4}{|c|}{ Men } & \multicolumn{4}{|c|}{ Women } \\
\hline & \multicolumn{2}{|c|}{ Univariate analysis } & \multicolumn{2}{|c|}{ Multivariate analysis } & \multicolumn{2}{|c|}{ Univariate analysis } & \multicolumn{2}{|c|}{ Multivariate analysis } \\
\hline & OR $[95 \% \mathrm{CI}]$ & $p$ & OR [95\% CI] & $p$ & OR [95\% CI] & $p$ & OR [95\% CI] & $p$ \\
\hline Age & $0.97[0.90-1.06]$ & .501 & & & $1.00[1.45-1.07]$ & .939 & & \\
\hline Education & $0.91[0.46-1.77]$ & .770 & & & $1.45[0.74-2.87]$ & .281 & & \\
\hline Residence & $0.79[0.39-1.58]$ & .507 & & & $1.30[0.76-2.24]$ & .333 & & \\
\hline Religion & $1.62[0.83-3.15]$ & .157 & & & 0.96 [0.58-1.59] & .880 & & \\
\hline Relationship length & $1.01[0.99-1.02]$ & .388 & & & $1.01[0.99-1.01]$ & .131 & & \\
\hline Age at first sexual encounter & $0.96[0.84-1.10]$ & .560 & & & $1.03[0.94-1.13]$ & .526 & & \\
\hline Number sexual partners & $0.54[0.29-1.00]$ & .051 & $0.76[0.37-1.56]$ & .449 & $0.57[0.36-0.92]$ & .020 & $0.89[0.53-1.50]$ & .665 \\
\hline Prior partner's infidelity & $1.67[0.81-3.43]$ & .165 & & & $0.73[0.46-1.16]$ & .184 & & \\
\hline Prior infidelity & $0.31[0.16-0.60]$ & .001 & $0.45[0.22-0.94]$ & .034 & $0.39[0.25-0.64]$ & $<.001$ & $0.53[0.31-0.90]$ & .020 \\
\hline Attitudes toward infidelity & $2.39[1.63-3.50]$ & $<.001$ & $1.69[1.09-2.55]$ & .018 & $1.99[1.56-2.55]$ & $<.001$ & $1.54[1.17-2.02]$ & .002 \\
\hline Satisfaction & $0.46[0.32-0.67]$ & $<.001$ & $0.66[0.39-1.10]$ & .110 & $0.65[0.52-0.82]$ & $<.001$ & $0.91[0.68-1.23]$ & .543 \\
\hline Commitment & $0.48[0.34-0.69]$ & $<.001$ & $0.90[0.53-1.55]$ & .703 & $0.56[0.45-0.70]$ & $<.001$ & $0.70[0.52-0.84]$ & .018 \\
\hline Investment & $0.83[0.60-1.14]$ & .239 & & & $0.95[0.74-1.20]$ & .642 & & \\
\hline Quality of alternatives & $2.04[1.43-2.90]$ & $<.001$ & $1.50[0.98-2.30]$ & .062 & $1.72[1.37-2.15]$ & $<.001$ & $1.25[0.97-1.62]$ & .091 \\
\hline
\end{tabular}

Note: Education $[0=\leq 12$ years: $1=>12$ years]; Residence $[0=$ Urban; $1=$ Rural $]$; Religion $[0=$ Catholic; $1=$ None $]$; Number of sexual partners in the last two years $[0=$

None; $1=$ More than 1$]$; Prior partner's infidelity $[0=$ No; $1=$ Yes $]$; Prior infidelity $[0=$ No; $1=$ Yes $]$. 
Table 4

Univariate and multivariate logistic regression analysis of correlates of face-to-face emotional EDI among men and women

\begin{tabular}{|c|c|c|c|c|c|c|c|c|}
\hline \multirow{3}{*}{ Variables } & \multicolumn{4}{|c|}{ Men } & \multicolumn{4}{|c|}{ Women } \\
\hline & \multicolumn{2}{|c|}{ Univariate analysis } & \multicolumn{2}{|c|}{ Multivariate analysis } & \multicolumn{2}{|c|}{ Univariate analysis } & \multicolumn{2}{|c|}{ Multivariate analysis } \\
\hline & OR $[95 \% \mathrm{CI}]$ & $p$ & OR $[95 \% \mathrm{CI}]$ & $p$ & OR $[95 \% \mathrm{CI}]$ & $p$ & OR $[95 \% \mathrm{CI}]$ & $p$ \\
\hline Age & $0.97[0.90-1.03]$ & .288 & & & $0.99[0.95-1.04]$ & .720 & & \\
\hline Education & $0.59[0.33-1.05]$ & .073 & $0.76[0.40-1.46]$ & .413 & $1.02[0.59-1.76]$ & .947 & & \\
\hline Residence & $0.67[0.35-1.28]$ & .228 & & & $1.04[0.72-1.52]$ & .822 & & \\
\hline Religion & 0.90 [0.51-1.57] & .704 & & & 1.07 [0.74-1.53] & .724 & & \\
\hline Relationship length & $1.00[0.99-1.01]$ & .987 & & & $1.01[1.00-1.02]$ & .002 & $1.01[1.00-1.02]$ & .001 \\
\hline Age at first sexual encounter & $0.91[0.82-1.02]$ & .114 & & & $0.90[0.83-0.96]$ & .004 & $0.92[0.86-0.99]$ & .040 \\
\hline Number sexual partners & $0.64[0.37-1.13]$ & .121 & & & $1.08[0.76-1.54]$ & .678 & & \\
\hline Prior partner's infidelity & $0.88[0.48-1.60]$ & .671 & & & $0.60[0.42-0.85]$ & .004 & $0.66[0.45-0.98]$ & .041 \\
\hline Prior infidelity & $0.57[0.30-1.08]$ & .084 & $0.85[0.42-1.73]$ & .652 & $0.56[0.38-0.84]$ & .005 & $0.71[0.45-1.11]$ & .134 \\
\hline Attitudes toward infidelity & $2.02[1.40-2.92]$ & $<.001$ & $1.45[0.96-2.20]$ & .080 & $1.51[1.23-1.86]$ & $<.001$ & $1.22[0.96-1.54]$ & .105 \\
\hline Satisfaction & $0.38[0.24-0.59]$ & $<.001$ & $0.55[0.32-0.94]$ & .029 & $0.54[0.44-0.67]$ & $<.001$ & $0.63[0.49-0.82]$ & $<.001$ \\
\hline Commitment & $0.35[0.21-0.57]$ & $<.001$ & $0.66[0.37-1.20]$ & .175 & $0.58[0.46-0.72]$ & $<.001$ & $0.85[0.64-1.13]$ & .259 \\
\hline Investment & $0.81[0.60-1.08]$ & .147 & & & $0.96[0.81-1.15]$ & .670 & & \\
\hline Quality of alternatives & $1.81[1.32-2.48]$ & $<.001$ & $1.27[0.89-1.82]$ & .193 & $1.63[1.35-1.97]$ & $<.001$ & 1.32 [1.06-1.64] & .012 \\
\hline
\end{tabular}

Note: Education $[0=\leq 12$ years: $1=>12$ years]; Residence $[0=$ Urban; $1=$ Rural $]$; Religion $[0=$ Catholic; $1=$ None $]$; Number of sexual partners in the last two years $[0=$

None; $1=$ More than 1]; Prior partner's infidelity $[0=$ No; $1=$ Yes $]$; Prior infidelity $[0=$ No; $1=$ Yes $]$. 
Table 5

Univariate and multivariate logistic regression analysis of correlates of online sexual EDI among men and women

\begin{tabular}{|c|c|c|c|c|c|c|c|c|}
\hline \multirow{3}{*}{ Variables } & \multicolumn{4}{|c|}{ Men } & \multicolumn{4}{|c|}{ Women } \\
\hline & \multicolumn{2}{|c|}{ Univariate analysis } & \multicolumn{2}{|c|}{ Multivariate analysis } & \multicolumn{2}{|c|}{ Univariate analysis } & \multicolumn{2}{|c|}{ Multivariate analysis } \\
\hline & OR $[95 \% \mathrm{CI}]$ & $p$ & OR $[95 \% \mathrm{CI}]$ & $p$ & OR $[95 \% \mathrm{CI}]$ & $p$ & OR $[95 \% \mathrm{CI}]$ & $p$ \\
\hline Age & $1.03[0.95-1.12]$ & .522 & & & $1.06[0.98-1.16]$ & .167 & & \\
\hline Education & $0.49[0.20-1.19]$ & .114 & & & $2.73[1.05-7.09]$ & .039 & $2.77[1.02-7.52]$ & .045 \\
\hline Residence & $0.48[0.22-1.04]$ & .064 & $0.43[0.18]$ & .064 & $2.12[0.72-6.26]$ & .174 & & \\
\hline Religion & $1.94[0.86-4.41]$ & .112 & & & $0.93[0.39-2.22]$ & .871 & & \\
\hline Relationship length & $1.01[0.99-1.02]$ & .171 & & & $1.00[0.98-1.01]$ & .721 & & \\
\hline Age at first sexual encounter & $0.94[0.80-1.10]$ & .416 & & & $1.01[0.86-1.19]$ & .899 & & \\
\hline Number sexual partners & $0.52[0.25-1.08]$ & .080 & $.067[0.28-1.58]$ & .358 & $0.40[0.18-0.88]$ & .023 & $0.57[0.24-1.32]$ & .190 \\
\hline Prior partner's infidelity & $0.92[0.42-2.02]$ & .839 & & & 0.89 [0.40-1.97] & .770 & & \\
\hline Prior infidelity & $0.44[0.21-0.93]$ & .032 & $0.69[0.29-1.61]$ & .390 & $0.38[0.17-0.85]$ & .018 & $0.54[0.22-1.32]$ & .178 \\
\hline Attitudes toward infidelity & $2.19[1.43-3.34]$ & $<.001$ & $1.66[1.01-2.73]$ & .046 & $1.66[1.13-2.35]$ & .009 & $1.34[0.86-2.07]$ & .196 \\
\hline Satisfaction & $0.41[0.27-0.62]$ & $<.001$ & $0.44[0.24-0.80]$ & .007 & $0.72[0.50-1.04]$ & .082 & $0.96[0.60-1.53]$ & .864 \\
\hline Commitment & $0.57[0.39-0.82]$ & .002 & $1.40[0.73-2.65]$ & .310 & $0.69[0.49-0.97]$ & .035 & $0.83[0.52-1.33]$ & .447 \\
\hline Investment & $0.63[0.44-0.92]$ & .015 & $0.81[0.51-1.30]$ & .387 & $0.94[0.62-1.42]$ & .758 & & \\
\hline Quality of alternatives & $1.67[1.13-2.47]$ & .010 & $1.43[0.86-2.37]$ & .170 & $1.53[1.07-2.20]$ & .020 & $1.16[0.77-1.74]$ & .480 \\
\hline
\end{tabular}

Note: Education $[0=\leq 12$ years: $1=>12$ years $]$; Residence $[0=$ Urban; $1=$ Rural $]$; Religion $[0=$ Catholic; $1=$ None $]$; Number of sexual partners in the last two years $[0=$

None; $1=$ More than 1]; Prior partner's infidelity $[0=$ No; $1=$ Yes $]$; Prior infidelity $[0=$ No; $1=$ Yes $]$. 
Table 6

Univariate and multivariate logistic regression analysis of correlates of online emotional EDI among men and women

\begin{tabular}{|c|c|c|c|c|c|c|c|c|}
\hline \multirow{3}{*}{ Variables } & \multicolumn{4}{|c|}{ Men } & \multicolumn{4}{|c|}{ Women } \\
\hline & \multicolumn{2}{|c|}{ Univariate analysis } & \multicolumn{2}{|c|}{ Multivariate analysis } & \multicolumn{2}{|c|}{ Univariate analysis } & \multicolumn{2}{|c|}{ Multivariate analysis } \\
\hline & OR $[95 \% \mathrm{CI}]$ & $p$ & OR $[95 \% \mathrm{CI}]$ & $p$ & OR $[95 \% \mathrm{CI}]$ & $p$ & OR $[95 \% \mathrm{CI}]$ & $p$ \\
\hline Age & $0.97[0.91-1.04]$ & .437 & & & $1.01[0.96-1.06]$ & .745 & & \\
\hline Education & $1.11[0.53-1.95]$ & .715 & & & $1.08[0.63-1.87]$ & .775 & & \\
\hline Residence & $0.64[0.35-1.18]$ & .151 & & & $1.20[0.82-1.76]$ & .350 & & \\
\hline Religion & $1.60[0.93-2.78]$ & .092 & $1.83[0.96-3.48]$ & .067 & $1.18[0.81-1.70]$ & .387 & & \\
\hline Relationship length & $1.00[0.99-1.01]$ & .565 & & & $1.01[0.99-1.01]$ & .120 & & \\
\hline Age at first sexual encounter & $0.94[0.84-1.05]$ & .250 & & & $0.94[0.87-1.00]$ & .056 & $0.97[0.90-1.05]$ & .415 \\
\hline Number sexual partners & $0.63[0.37-1.08]$ & .090 & $0.79[0.41-1.72]$ & .483 & $0.87[0.61-1.24]$ & .440 & & \\
\hline Prior partner's infidelity & $0.98[0.55-1.75]$ & .974 & & & $0.54[0.38-0.77]$ & .001 & $0.64[0.44-0.94]$ & .022 \\
\hline Prior infidelity & $0.60[0.33-1.09]$ & .095 & $0.95[0.47-1.96]$ & .895 & $0.43[0.29-0.63]$ & $<.001$ & $0.53[0.34-0.81]$ & .003 \\
\hline Attitudes toward infidelity & $1.64[1.19-2.27]$ & .003 & $1.00[0.66-1.50]$ & .979 & $1.37[1.13-1.66]$ & .001 & $1.09[0.87-1.36]$ & .458 \\
\hline Satisfaction & $0.27[0.17-0.42]$ & $<.001$ & $0.27[0.15-0.47]$ & $<.001$ & $0.54[0.44-0.66]$ & $<.001$ & $0.57[0.45-0.73]$ & $<.001$ \\
\hline Commitment & $0.40[0.27-0.60]$ & $<.001$ & $0.83[0.47-1.89]$ & .540 & $0.67[0.55-0.81]$ & $<.001$ & $1.04[0.81-1.35]$ & .746 \\
\hline Investment & $0.79[0.60-1.04]$ & .095 & $1.32[0.91-1.92]$ & .148 & $0.95[0.79-1.13]$ & .539 & & \\
\hline Quality of alternatives & $1.75[1.30-2.36]$ & $<.001$ & $1.38[0.95-2.01]$ & .089 & $1.53[1.28-1.84]$ & $<.001$ & $1.29[1.04-1.58]$ & .018 \\
\hline
\end{tabular}

Note: Education $[0=\leq 12$ years: $1=>12$ years]; Residence $[0=$ Urban; $1=$ Rural]; Religion $[0=$ Catholic; $1=$ None $]$; Number of sexual partners in the last two years $[0=$ None; $1=$ More than 1]; Prior partner's infidelity $[0=$ No; $1=$ Yes $]$; Prior infidelity $[0=$ No; $1=$ Yes $]$. 